\title{
Satisfaction of pharmacy students with e-learning approach in the University of Health Sciences Casablanca, Morocco during COVID-19 lockdown
}

\author{
Lamia Slimani $^{1,2}$ (D) Layla Hammidi ${ }^{1,2}$, Fayssal Jhilal ${ }^{1,2}$, Chakib Nejjari ${ }^{2,3}$, Samir Ahid ${ }^{1,2}$ \\ ${ }^{1}$ Faculty of Pharmacy, Mohammed VI University of Health Sciences (UM6SS), Casablanca, Morocco \\ ${ }^{2}$ Methodological Support Unit, Mohammed VI University of Health Sciences (UM6SS), Casablanca, Morocco \\ ${ }^{3}$ Mohammed VI University for Health Sciences, Casablanca, Morocco
}

Keywords
COVID-19
e-learning
Health education
Lockdown
Pharmacy
Correspondence
Lamia Slimani
Faculty of Pharmacy
Mohammed VI
University of Health Sciences (UM6SS)
Casablanca
Morocco
Islimani@um6ss.ma

\section{Introduction}

The severe acute respiratory syndrome coronavirus 2 (SARS-COV-2) is one of the main pathogens that mainly targets the human respiratory system. This virus was responsible for the new coronavirus 2019 (2019-nCOV) that appeared in December 2019 in Wuhan city, a metropolis with 11 million inhabitants in the heart of China (Singhal, 2020).

The SARS-COV-2 virus, then, quickly spread to the rest of the world, which prompted the World Health Organization (WHO) to declare this disease as a

\begin{abstract}
Objective: The aim of this study was to assess the satisfaction of pharmacy students with elearning during the COVID-19 lockdown. Methods: A cross-sectional study was conducted in the Pharmacy School of Mohammed VI University of Health Sciences of Casablanca in April 2020. An anonymous questionnaire previously validated by the pedagogical committee of the university was administered to students via google forms. Results: A total of 154 responses were received, $122(79.22 \%)$ were female students. The majority of students were satisfied the general organisation (between $60.4 \%$ and $81.8 \%$ depending on the studied parameter), e-learning (63.6\%), educational content (between $61 \%$ and $85.7 \%$ depending on the studied parameter), self-assessment methods (between $64.9 \%$ and $84.4 \%$ depending on the studied parameter), adaptation (63\%), the involvement of teachers $(83.8 \%)$, and the administration of the faculty (75.9\%). Multivariate analysis showed that two factors were significantly associated with student satisfaction related to e-learning in this study. This corresponds to the level of study ( $p$-value $=0.026$; OR=4.009; I $C_{95 \%}[1.176-13.663]$ ) and the adaptation ( $p$-value $=0.004 ; \mathrm{OR}=3.671 ; \mathrm{IC}_{95 \%}[1.519-8.868]$ ). This study found that satisfaction levels were higher among third year students, which could be interpreted by the fact that they were more familiar with e-learning. Conclusion: Students were mostly satisfied with elearning during the lockdown. The experience from this study showed an advantage for other schools by the partial introduction of e-learning training as a teaching method in normal situations in order to better deal with emergency situations.
\end{abstract}

pandemic on 11 March 2020 (World Health Organisation, nd; Pelmin, 2020; Wang et al., 2020). Indeed, several cases have been notified in other countries such as Thailand, Japan and South Korea. The first case of death from this virus was reported on 11 January 2020 (Singhal T, 2020). Subsequently, an exponential increase in the number of deaths, as well as cases of infection, have been observed worldwide (Wang et al., 2020). This induced all of the affected countries to put in place a curfew and thus oblige citizens to confine themselves at home. 
The Moroccan authorities introduced a state of health emergency on 20 March 2020, from the first cases that appeared, with the lockdown of the population. The lockdown was extended four times (Anon, 2020). Thus, the Moroccan government took the necessary measures to prohibit people from leaving their homes except for absolute necessity and also prohibit any gatherings or meetings of groups of people as well as any business that can accommodate the public. Consequently, several sectors of activity were affected, including the education sector.

In the context of COVID-19, the university environment has undergone massive reforms on a global scale. Health education has also been highly affected by this emergency health situation. Therefore, faced with this global crisis, in order to allow pedagogical continuity for students and avoid a premature end of the academic year, Moroccan universities quickly switched to a model of distance education and supervision. In this respect, the Faculty of Pharmacy of Mohammed VI University of Health Sciences (UM6SS) of Casablanca, through the pedagogical e-learning platform "CANVAS" adopted by the university, switched its system of education to e-learning training. Indeed, the Faculty of Pharmacy of UM6SS has partially adopted this elearning training since its opening in the 2017-2018 academic year, and distance education represented $50 \%$ of the total hourly volume of each module taught in the faculty. Two distance learning approaches are described in the literature: synchronous and asynchronous. The first approach involves students learning together and live such as in lectures; this allows them to acquire a certain level of commitment and a sense of community. Conversely, the asynchronous learning approach allows students, thanks to the material communicated to them, to learn by themselves and to discuss the content in forums, for example. They, thus, have time to complete their course synthesis to the detriment of community involvement (Offir, Lev \& Bezalel, 2007; Watts, 2016; Chen, Kaczmarek \& Ohyama, 2020).

In addition, the total and urgent switchover from faceto-face learning to distance education required mobilisation and adaptation on the part of students, teachers and also the administrative staff. In fact, the students naturally followed the approach established by the faculty, hoping that it would be as effective as face-to-face teaching. During this period of lockdown, the faculty faced some challenges related to the planning of the normal period, to work in pedagogical teams in order to ensure the continuity of the training synchronously and asynchronously, as well as accompanying the students through the forums.
In recent years, several studies have focused on evaluating the effectiveness of the implementation of e-learning as a teaching approach (Govindasamy, 2001; Gotthardt, Siegert \& Schlieck, 2006; Muirhead, 2007; Popovici A \& Mironov, 2015; Vitoria, Mislinawati \& Nurmasyitah, 2018; Chen, Kaczmarek \& Ohyama, 2020). Some works have described an appreciation of students for e-learning training as a teaching method which has been recommended by several universities around the world (Govindasamy, 2001; Martín-Blas \& Serrano-Fernández, 2009). Another study carried out among nursing and medical students had shown their preference for the e-learning approach in the future (Gruner, Pottie \& Archibald, 2015; Jamil, Sethi \& Ali, 2016). Also, a study of pediatric cardiology students described a high level of student satisfaction with the e-learning approach (Maheshwari et al., 2015).

The goal of this paper is to assess the satisfaction rate of pharmacy students with the e-learning training offered during lockdown due to COVID-19 and to suitably reveal which parameters impact exactly this rate by applying some biostatistical methods such as cross tables, univariate analysis and multivariate analysis.

\section{Methods}

This is a descriptive analytical prevalence study conducted within the Faculty of Pharmacy of Mohammed VI University of Health Sciences during April 2020.

An anonymous questionnaire intended to assess the progress of the educational system established by the faculty was administered to the different students during lockdown via google forms. The questionnaire consisted of 26 elements which were grouped into six categories. So, the authors evaluated student's satisfaction with various parameters relating to the general organisation such as the weekly schedule of courses in the Faculty of Pharmacy, the fixed course schedules, the structuring of the courses and assessments on the e-learning platform "CANVAS". This platform is an open-source Learning Management System (LMS), published by Instructure Inc., in Salt Lake City (United States). Its "standard" version targets higher education institutions.

The authors were also interested in the satisfaction of the students with regard to the relevance of the recorded capsules, the posting of the PDF courses on the platform, the clarity of the educational objectives and also their appreciation for live conferences (courses, tutorials and correction of exercises).

Self-assessment was also evaluated through the student's regular response to the quizzes, the clarity 
and relevance of the quiz, the number of quizzes assigned per session, the number of attempts authorized per quiz, as well as the deadline for quiz submission (48 hours per session).

The evaluation of student interactivity with teachers via the forums was also completed. The authors questioned the students on the usefulness of the forums and their regular usage of the forums made available to them as well as their appreciation for the deadline of interactivity of these forums ( 48 hours per session).

The authors also assessed the level of student satisfaction with e-learning training during this period, their appreciation of the teaching model during this period, as well as their degree of adaptation to follow the courses at home. Eventually, the authors assessed the student's feedback in terms of satisfaction with the degree of involvement of teachers in the quality of training and the level of responsiveness of the faculty administrative staff in relation to their requests.

Several systems have been put in place on the elearning platform that is available to teachers and students to achieve educational continuity during lockdown through synchronous and asynchronous learning. The terms of which have been previously validated by the university's pedagogical commission. In fact, synchronous learning focused mainly on lessons or tutorials, allowing teachers and students to instantly exchange information on the content of teaching; thus, 141 live conferences were scheduled during the lockdown. As part of the asynchronous teaching, 192 narrated power-point and short videos (directed and practical courses) were produced; a forum was associated with each deposited short video in order to ensure and facilitate the reactivity between teachers and students with a total of 137 forums as well as 190 quizzes.

The data were entered into Excel and analysed through SPSS version 26.0 software. Qualitative variables were expressed in number and percentage. Qualitative variables were expressed as mean and standard deviation or median and quartile. The factors associated with satisfaction of the teaching method were studied in univariate and multivariate analyses using the binary logistic regression model (enter method). The significance level has been set at $p<0.05$.

\section{Results}

Out of a total of 180 pharmacy students, 154 of them responded to the questionnaire (around 84\%). The participating students were divided into 122 girls (79.2\%) and 32 boys (20.8\%). The average age was 20.4 . These students were enrolled in the first, second and third years of pharmaceutical studies, which represents $15.6 \%, 41.6 \%$ and $42.9 \%$ of total participating students, respectively. Also, the vast majority of these students were confined with their families (93.5\% vs 6.5\%) (Table I).

Table I: Demographic data

\begin{tabular}{lll}
\hline Categories & $\mathbf{n}(\%)$ & Mean \pm standard deviation \\
\hline Gender: & $32(20.8)$ & $20.8 \pm 2.8$ \\
Male & $122(79.2)$ & \\
Female & & \\
Age (year): & $24(15.6)$ \\
\hline Level of study: & $64(41.6)$ \\
First year & $66(42.9)$ \\
Second year & $10(6.5)$ \\
Third year & $144(93.5)$ \\
\hline Containment mode: & \\
Alone & \\
With family &
\end{tabular}

The authors were first interested in evaluating the student's satisfaction with the general organisation proposed in terms of weekly planning, fixed schedules as well as the arrangement of courses and assessments on the "CANVAS" educational platform. The students were satisfied with the volume of teaching offered $(60.4 \%)$, the timetables set for distance education (75.3\%) as well as the structuring of the courses and assessments on the elearning platform (81.8\%). The authors also assessed the relevance of the educational materials offered to students during the lockdown and their contribution to this distance learning approach (Table II). 
Table II: Student satisfaction level with the general organisation, educational content and involvement of teachers and administrative staff during lockdown

\begin{tabular}{|c|c|c|c|c|}
\hline & $\begin{array}{c}\text { Very satisfied } \\
\text { n (\%) }\end{array}$ & $\begin{array}{l}\text { Satisfied } \\
\text { n (\%) }\end{array}$ & $\begin{array}{c}\text { Moderately } \\
\text { satisfied } \\
\text { n (\%) }\end{array}$ & $\begin{array}{c}\text { Not at al } \\
\text { satisfied } \\
\text { n (\%) }\end{array}$ \\
\hline Weekly schedule of courses & $11(7,2)$ & $82(53,2)$ & $56(36,4)$ & $5(3,2)$ \\
\hline Fixed course schedules & $17(11)$ & $99(64,3)$ & $30(19,5)$ & $8(5,2)$ \\
\hline $\begin{array}{l}\text { Structuring of the courses and assessments on the e- } \\
\text { learning platform }\end{array}$ & $23(14,9)$ & $103(66,9)$ & $25(16,2)$ & $3(2)$ \\
\hline Clarity of the educational objectives & $9(5,8)$ & $96(62,3)$ & $45(29,2)$ & $4(2,6)$ \\
\hline Relevance of the recorded capsules & $13(8,4)$ & $81(52,6)$ & $50(32,5)$ & $10(6,5)$ \\
\hline Posting of the PDF support courses & $41(26,6)$ & $91(59,1)$ & $21(13,6)$ & $1(0,7)$ \\
\hline Usefulness of lectures & $35(22,7)$ & $76(49,4)$ & $33(21,4)$ & $10(6,5)$ \\
\hline Usefulness of tutorials & $45(29,2)$ & $76(49,4)$ & $32(20,8)$ & $1(0,7)$ \\
\hline Content of exercises and their correction by teachers & $24(15,6)$ & $84(54,6)$ & $38(24,7)$ & $8(5,2)$ \\
\hline Involvement of teachers in the quality of training & $38(24,7)$ & $91(59,1)$ & $24(15,6)$ & $1(0,7)$ \\
\hline Responsiveness of the administration to requests & $29(18,8)$ & $88(57,1)$ & $31(20,1)$ & $6(3,9)$ \\
\hline
\end{tabular}

Indeed, capsules of 20 to 30 minutes were recorded by the teachers of the faculty for each session and made available to students according to the schedule communicated. The results of the survey showed that the students were satisfied with the relevance and the quality of these educational materials offered (61.0\%), the clarity of the educational objectives (68.1\%), as well as the online publication of the PDF support course (85.7\%). In addition, the feedback from students showed that the lectures and "live" tutorials were also very useful to them during this lockdown period, with a satisfaction percentage of $72.1 \%$ and $78.6 \%$ for the lectures and tutorials, respectively. As part of these tutorials, professors published a week before the live tutorial session along with a series of exercises to which the students had to respond, and the correction was then organised during the tutorial session (Table II).

According to the results of the questionnaire, the percentage of students who expressed their satisfaction with the content of the exercises and with their correction was $70.2 \%$. In addition, students were also asked about the possible need for other types of documents or additional media during this lockdown period. The results showed that $76 \%$ of the students did not express any particular need for documents. Finally, the students expressed their satisfaction with the involvement of teachers and the responsiveness of the Faculty of Pharmacy administration to their requests with percentages of $83.8 \%$ and $75.9 \%$, respectively (Table II).

Self-assessment methods offered to students were also surveyed through the frequency of student's responses to quizzes submitted, the clarity and relevance of the quiz as well as the number of quizzes assigned per session. The evaluation showed that all of the students answered the quizzes, with $89.6 \%$ of students who tried to answer all of the questions proposed. In addition, students seemed to be satisfied with the clarity and relevance of the quizzes (64.9\%) as well as the number of quizzes assigned for each online course session $(84.4 \%)$. The number of attempts allowed per quiz would be satisfactory for around $80 \%$ of the students. However, the majority of students (53.3\%) were dissatisfied with the deadline for quiz submission set at 48 hours by the faculty (Table III).

This study indicated that out of 154 students, $48.7 \%$ of them declared that they often or always use the forums against $51.3 \%$ of the students who rarely or never use it. However, the usefulness of this exchange forum is expressed by the majority of students (55.8\%). Also, $60.4 \%$ of students said that the period of interactivity in the forum (48 hours/session) was sufficient to interact with the teachers (Table III).

Finally, the authors assessed student's satisfaction with distance learning as well as their adaptation during the lockdown. The results showed that $63.6 \%$ of the students were satisfied with distance learning, against $36.4 \%$ who were a little or not satisfied. Additionally, $75.3 \%$ of the students expressed their satisfaction with the teaching model proposed by the faculty, against $24.7 \%$ who were a little or not satisfied with this teaching model. These results are very close to those of the assessment of the adaptation of students during the lockdown. In fact, $63 \%$ of students declared an easy or fairly easy adaptation compared to $37 \%$, for whom adaptation was difficult during the lockdown (Table III). 
Table III: Student satisfaction level with self-assessment methods, usefulness of forums, distance learning approach as well as adaptation during lockdown

\begin{tabular}{|c|c|c|c|c|}
\hline & $\begin{array}{c}\text { Very satisfied } \\
\text { n (\%) }\end{array}$ & $\begin{array}{l}\text { Satisfied } \\
\text { n (\%) }\end{array}$ & $\begin{array}{c}\text { Moderately } \\
\text { satisfied } \\
\text { n (\%) }\end{array}$ & $\begin{array}{c}\text { Not at all satisfied } \\
\mathrm{n}(\%)\end{array}$ \\
\hline $\begin{array}{l}\text { Clarity and relevance of the } \\
\text { quizzes }\end{array}$ & $19(12,3)$ & $81(52,6)$ & $51(33,1)$ & $3(2)$ \\
\hline Number of quizzes & $31(20,1)$ & $99(64,3)$ & $24(15,6)$ & $0(0)$ \\
\hline $\begin{array}{l}\text { Number of attempts allowed } \\
\text { per quiz }\end{array}$ & $24(15,6)$ & $71(64,1)$ & $46(29,9)$ & $13(8,4)$ \\
\hline $\begin{array}{l}\text { Deadline for quiz submission } \\
(48 \mathrm{~h})\end{array}$ & $23(14.9)$ & $49(31.8)$ & $76(49.4)$ & $6(3.9)$ \\
\hline $\begin{array}{l}\text { Usefulness of exchange } \\
\text { forums }\end{array}$ & $11(7,1)$ & $75(48,7)$ & $55(35,7)$ & $13(8,4)$ \\
\hline $\begin{array}{l}\text { Period of interactivity in the } \\
\text { forum }\end{array}$ & $9(5,8)$ & $84(54,6)$ & $39(25,3)$ & $22(14,3)$ \\
\hline $\begin{array}{l}\text { General appreciation with } \\
\text { distance learning }\end{array}$ & $19(12,3)$ & $79(51,3)$ & $52(33,8)$ & $4(2,6)$ \\
\hline Teaching model & $25(16,2)$ & $91(59,1)$ & $35(22,7)$ & $3(2)$ \\
\hline $\begin{array}{l}\text { Adaptation to follow the } \\
\text { lessons at home }\end{array}$ & $24(15,6)$ & $73(47,4)$ & $54(35)$ & $3(2)$ \\
\hline
\end{tabular}

The authors carried out univariate and multivariate analyses to determine the factors that are at the origin of the general student's appreciation of e-learning training during the lockdown. The results of the univariate analysis showed that the factors associated with the satisfaction of students with e-learning education were: the level of study $(p=0.004 ; \mathrm{OR}=4.375$; $\left.I_{95 \%}[1.599-11.968]\right)$, the weekly course schedule $\left(p<0.001 ; \mathrm{OR}=3.695 ; \mathrm{IC}_{95 \%}\right.$ [2.035-6.71]), the relevance of the sound courses $(p<0.001$; OR=3.089; IC $95 \%$ [1.689$5.65])$, the clarity of the educational objectives $\left(p<0.001 ;\right.$ OR=3.089; I $C_{95 \%}$ [1.689-5.65]), the clarity and relevance of the quizzes ( $p=0.027 ; \mathrm{OR}=1.756 ; \mathrm{IC}_{95 \%}$ [1.065-2.897]), the adaptation to follow the lessons at home during lockdown $\left(p<0.001 ; \mathrm{OR}=4.75 ; \quad \mathrm{IC}_{95 \%}\right.$ [2.594-8.697]), the involvement of teachers in the quality of training $(p<0.001 ; \mathrm{OR}=3.357$; IC $95 \%$ [1.8396.128]) and finally the involvement of the administration of the faculty $\left(p<0.001 ; \mathrm{OR}=3.213 ; \mathrm{IC}_{95 \%}\right.$ [1.863-5.54]).

However, in the multivariate analysis, only two factors were associated with student satisfaction with elearning training during the lockdown. It was 1) the level of study ( $p=0.026 ; \quad O R=4.009 ; \quad C_{95 \%}$ [1.17613.663]); and 2) the adaptation, which means the ability of students to take classes at home ( $p=0.004$; $\mathrm{OR}=3.671 ; \quad$ IC95\% [1.519-8.868]). So the satisfied students were those who adapted well to the lockdown and were third year students, as they were mostly used to the e-learning training that was partially implemented by the Faculty of Pharmacy three years ago (Table IV).

As for the main strong and weak points of this teaching model, the students evoked, for the strong points, that it allowed them to have a good pedagogical continuity during the lockdown period and that the model was motivating and of good quality. It also allowed students to manage their time at their convenience as the sound courses and quizzes helped the students stay up to date, they were efficient and interactive, ensured regularity of communication with the teachers and the administration of the faculty, had access to home lessons, the possibility to spend time with family, it allowed students to develop a certain autonomy through self-learning, and it was less stressful. Concerning the main weaknesses of this teaching model according to the students: there was a decrease in interactivity between teachers and students as well as between students themselves compared to face-toface courses, no access to the correction of quizzes, obligation to follow the fixed timetables that were also overly busy and concern about the modalities of the controls and exams. They would also have liked to have more live lectures and to have been provided more time to understand the lessons alone. Students experienced a decrease in motivation, they did not like the changeover of practical work in the digital form and were faced with internet connection problems. 
Table IV: Univariate and multivariate analyses of the factors associated with student satisfaction with the proposed e-learning training: A binary logistic regression model

\begin{tabular}{|c|c|c|c|c|c|c|c|c|c|c|}
\hline & \multirow{3}{*}{$\begin{array}{c}\text { Negative } \\
\text { satisfaction } \\
n(\%)\end{array}$} & \multirow{3}{*}{$\begin{array}{c}\text { Positive } \\
\text { satisfaction } \\
n(\%)\end{array}$} & \multicolumn{4}{|c|}{ Univariate analysis } & \multicolumn{4}{|c|}{ Multivariate analysis } \\
\hline & & & \multirow[t]{2}{*}{$p$} & \multirow[t]{2}{*}{ OR } & \multicolumn{2}{|c|}{$\mathrm{IC}_{95 \%}$} & \multirow[t]{2}{*}{$p$} & \multirow[t]{2}{*}{ Adjusted OR } & \multicolumn{2}{|c|}{$\mathrm{IC}_{95 \%}$} \\
\hline & & & & & Inf & Sup & & & Inf & Sup \\
\hline Level of study: & $13(54.2)$ & $11(45.8)$ & & 1 & & & & 1 & & \\
\hline \multicolumn{11}{|l|}{ - First year } \\
\hline - Second year & $28(43.8)$ & $36(56.3)$ & 0.353 & 1.57 & 0.606 & 4.065 & 0.053 & 3.156 & 0.987 & 10.088 \\
\hline - Third year & $15(22.7)$ & $51(77.3)$ & 0.004 & 4.375 & 1.599 & 11.968 & 0.026 & 4.009 & 1.176 & 13.663 \\
\hline Gender : & $41(33.6)$ & $81(66.4)$ & 0.168 & 1 & 0.792 & 3.839 & 0.351 & 1 & 0.598 & 4.247 \\
\hline - Male & & & & 1.743 & & & & 1.594 & & \\
\hline \multicolumn{11}{|l|}{ - Female } \\
\hline Containment mode: & $52(36.1)$ & $92(63.9)$ & 0.805 & 1 & 0.318 & 4.372 & 0.219 & 1 & 0.547 & 13.85 \\
\hline - Alone & & & & 1.179 & & & & 2.753 & & \\
\hline \multicolumn{11}{|l|}{ - With family } \\
\hline Weekly course schedule & $20(21.5)$ & $73(78.5)$ & $<0.001$ & 3.695 & 2.035 & 6.71 & 0.076 & 2.16 & 0.922 & 5.063 \\
\hline Relevance of the sound courses & $25(26.6)$ & $69(73.4)$ & $<0.001$ & 3.089 & 1.689 & 5.65 & 0.14 & 1.93 & 0.806 & 4.617 \\
\hline $\begin{array}{l}\text { Clarity of the educational } \\
\text { objectives }\end{array}$ & $28(26.7)$ & $77(73.3)$ & $<0.001$ & 3.089 & 1.689 & 5.65 & 0.242 & 1.766 & 0.682 & 4.572 \\
\hline Relevance of tutorials & $34(31.5)$ & $74(68.5)$ & 0.076 & 1.49 & 0.959 & 2.316 & 0.847 & 1.101 & 0.415 & 2.922 \\
\hline $\begin{array}{l}\text { Clarity and relevance of the } \\
\text { quizzes }\end{array}$ & $29(29)$ & $71(71)$ & 0.027 & 1.756 & 1.065 & 2.897 & 0.843 & 1.095 & 0.445 & 2.695 \\
\hline Usefulness of forums & $29(33.7)$ & $57(66.3)$ & 0.094 & 1.464 & 0.937 & 2.287 & 0.975 & 1.014 & 0.429 & 2.399 \\
\hline $\begin{array}{l}\text { Adaptation to follow the lessons } \\
\text { at home }\end{array}$ & $21(21.6)$ & $76(78.4)$ & $<0.001$ & 4.75 & 2.594 & 8.697 & 0.004 & 3.671 & 1.519 & 8.868 \\
\hline $\begin{array}{l}\text { Involvement of teachers in the } \\
\text { quality of training }\end{array}$ & $39(30.2)$ & $90(69.8)$ & $<0.001$ & 3.357 & 1.839 & 6.128 & 0.437 & 1.675 & 0.456 & 6.153 \\
\hline $\begin{array}{l}\text { Responsiveness of the } \\
\text { administration to requests }\end{array}$ & $33(28.2)$ & $84(71.8)$ & $<0.001$ & 3.213 & 1.863 & 5.54 & 0.433 & 1.534 & 0.527 & 4.467 \\
\hline
\end{tabular}

n: number of students; \%: percentage; p: p-value; OR: Odds Ratio; Inf: Inferior; Sup: Superior; IC95\%: 95\% Confidence Interval, 1 represents the reference group CI.

\section{Discussion}

In this study, the authors were interested in the overall perception of pharmacy students towards e-learning during lockdown due to COVID-19. Several parameters were thus evaluated. The results of the survey showed that the majority of students were satisfied with the general organisation, e-learning, educational content, self-assessment methods, adaptation, as well as the involvement of teachers and the administration of the faculty. However, the results also indicated that the majority of students were dissatisfied with the deadline of quiz submission and also that they rarely or never used online forums. The satisfied students were those who adapted well to lockdown and were mainly third year students. These results go hand in hand with those of Yilmaz in 2017, who showed that the preparation for online learning of students was linked to their satisfaction and their motivation when performing academic tasks in the flipped classroom (Yilmaz, 2017). In addition, student satisfaction with sound courses during the lockdown was in accordance with the study of Münch-Harrach and authors in 2013 who showed that audio podcasts have been used by the medical students extensively and have also been evaluated very positively by non-student listeners (Münch-Harrach, Kothe \& Hampe, 2013). Moreover, podcasts are already being used in medical school curricula (Harvard Medical School, nd; Boulos, Maramba \& Wheeler, 2006; Singh, Alam \& Matava, 2016).

Regarding the lack of regularity relative forums, this may be due to the fact that students would have preferred to ask their questions on "live" to the teachers or also because of limitations in communication skills that may limit student participation as well as difficulties in logistics as described by Simpson and authors (2008). Or also due to a need for a moderator/tutor to better manage forums and then encourage user participation as described by Ortega-Morán and the authors (2020).

Regarding the dissatisfaction with the deadline of quiz submission, this can be explained by the fact that the 
students found difficulties in understanding the questions, or that the questions were not directly related to the capsule submitted online, or also due to the fact that items contained flaws and were written at the knowledge/comprehension level as partially suggested by Larson and authors (2009) and Janzen and authors (2019).

With regard to the factors behind the difficult adaptation of some students to follow home lessons, this may be due to depression, an environment that is not suitable for studying and finally, internet connection problems as described by "undergraduate" and "postgraduate" students in India (Kapasia et al., 2020).

Among the advantages of distance learning are convenience and accessibility; as to the limits, the authors can cite inefficiency and difficulty of maintaining academic equality (Mukhtar et al., 2020). According to teachers and students, distance education had encouraged student-centeredness during lockdown due to COVID-19 (Mukhtar et al., 2020). However, the majority of recently published studies during lockdown due to COVID-19 described students' dissatisfaction with e-learning training imposed and thus had a preference for face-to-face teaching (Owusu-Fordjour, Koomson \& Hanson, 2020; Zhang et al., 2020). Indeed, many institutions were not well prepared for the e-learning challenge. Schools of Pharmacy were no exception, as they were not ready for a disruptive and complete transition in curriculum delivery (Qandil \& Abdel-Halim, 2020). The experience of the fresh Faculty of Pharmacy showed the advantage that can be brought by the partial introduction of e-learning training as a teaching method in normal situations to better deal with emergency situations.

A recent paper has also presented some instructional strategies to improve student focus and engagement in learning with the goal of ensuring a smooth transition to online learning (Bao, 2020). Among the proposals mentioned by the author are the development of emergency preparedness plans by switching to an online education mode which would require adapting computer servers to be able to host such a large scale of new users. Due to the possible overload of the usage of these servers and therefore a possibility of stopping their operation, professors must always have alternative plans for each online course and inform the students in advance. In addition, they should always divide the content of the course planned face-to-face into several sound capsules corresponding to the different chapters of the course. Finally, the progress of online education and its learning effectiveness is largely dependent on students' active learning outside the classrooms. So, teachers should innovate and diversify homework methods to stimulate students' active learning outside the classrooms (Bao, 2020).

Students' clinical practice was also affected during this COVID-19 period, and universities have thus sought mechanisms to ensure pedagogical continuity. The paper written by Roskvist's and the authors (2020) described the e-learning programme components they offered, which was manifested in three components: asynchronous discussion forums, a symposium facilitating social interactions and teacher presence, and a portfolio facilitating personal goal aspects. Another study reported the learning efficiency of human anatomy using the Zoom video conferencing platform (Zoom Video Communications, Inc., San Jose, CA) in Singapore (Srinivasan, 2020). Furthermore, Zingaretti's (2020) paper presented some tools that can be reliable solutions to improve the training of plastic residents, mainly during the COVID-19 pandemic. Among these tools, there is the Touch Surgery application available on smartphones and tablets, which gives the possibility to watch real and virtually designed surgical videos, which are interactive and provide students with the possibility to check what they have learned through tests administered after virtual classes. Moreover, the academic user-friendly touch screen table "Anatomage" can be used by both medical students and residents to learn human anatomy and to master surgical anatomy (Zingaretti et al., 2020). In addition, the diversification of learning activities would facilitate the engagement of students since they were raised with technology. The ability to learn and revise at your own pace, with no time or place required, leads to better educational prospects (Gupta \& Gupta, 2016; Rajhans et al., 2020).

One of the limitations of this study is that questions assessing students' feedback on digitised practical work were not introduced in the questionnaire. This was due to the fact that the practical work was scheduled for the end of the semester, and it was believed that the lockdown would have come to an end before this and that students would have returned to face to face teaching. Another limitation of this study is that the presence of only three promotions of students within the Faculty of Pharmacy has only existed since the 2017/2018 academic year.

In application of this work and with the objective of better coping with possible emergency situations, the authors recommend that other schools of pharmacy to:

1) Acquire a digital educational platform to be ready to switch completely to distance education if necessary.

2) Train teachers in digital pedagogy.

3) Train students in educational platforms.

4) Include e-learning in the curriculum to complement teaching and learning in the classroom in order to 
better cope with emergency situations and also to develop students' self-learning capacities.

5) Create a permanent exchange between teachers and students through discussion forums available on digital educational platforms.

6) Mix synchronous teaching (for tutorials) and asynchronous teaching (for lectures).

7) Introduce a "learning methodology class" into the curriculum that will allow students to acquire the tools and skills necessary for online learning.

8) Increase students' self-assessment tests so that they can better follow online courses. The distance learning experience is an increasingly used educational practice that presents opportunities in emergency situations. The distance learning approach can be further developed by integrating more and more interaction between students and teachers, for example: integrating more workshops in small groups as well as serious online games in which the teacher could divert entertainment games for educational purposes. Indeed, the more attractive the content, the better learners retain information. It would also be interesting to develop virtual practical classes. Inviting students to prepare oral presentations on different themes related to the curriculum could better engage them and also develop their sense of responsibility.

Finally, it would also be interesting to assess the internship courses for student pharmacists during health emergencies in order to identify the skills that are acquired or improved.

\section{Conclusion}

The pharmacy students were mostly satisfied with elearning during the lockdown. The main reasons for this satisfaction were the level of study as well as their ability to adapt since their introduction to e-learning. Therefore, this current study recommends that students should be introduced to e-learning platforms to supplement classroom teaching and learning during "normal situations" in order to better deal with emergency situations.

\section{Acknowledgements}

The authors gratefully acknowledge the contribution of Professor Abdeslam CHETIOUI for proofreading the manuscript. The authors also acknowledge the support of the educational and administrative staff of the Faculty of Pharmacy (Mariyem KAMEL, Mourad SAROUI,
Mohamed BANADDI, Hasna SFAIRAT and Meryem ELATTAOUI).

\section{Conflicts of interest}

The authors declare no conflict of interest.

\section{References}

Bao W. COVID-19 and online teaching in higher education: A case study of Peking University. Hum Behav Emerg Technol. 2020; 2(2):113-115.https://doi.org/10.1002/hbe2.191

Boulos MNK, Maramba I, Wheeler S. Wikis, blogs and podcasts: a new generation of Web-based tools for virtual collaborative clinical practice and education. BMC Med Educ. 2006;6:41. https://doi.org/10.1186/1472-6920-6-41

Chen E, Kaczmarek K, Ohyama H. Student perceptions of distance learning strategies during COVID-19. J Dent Educ. Published online July 2020. https://doi.org/10.1002/jdd.12339

Gotthardt M, Siegert MJ, Schlieck A, et al. How to successfully implement E-learning for both students and teachers. Published online 2006.

https://doi.org/10.1016/j.acra.2005.12.006

Govindasamy T. Successful implementation of e-learning: Pedagogical considerations. internet High Educ. 2001;4(34):287-299. https://doi.org/10.1016/S1096-7516(01)00071-9

Gruner D, Pottie K, Archibald D, et al. Introducing global health into the undergraduate medical school curriculum using an e-learning program: a mixed method pilot study. BMC Med Educ. 2015; 15(1):142.

https://doi.org/10.1186/s12909-015-0421-3

Gupta VK, Gupta VB. Using technology, bioinformatics and health informatics approaches to improve learning Experiences in optometry education, research and practice. In: Healthcare. Vol 4. Multidisciplinary Digital Publishing Institute; 2016:86. https://doi.org/10.3390/healthcare4040086

Harvard Medical School - WebWeekly. Available at: http://webweekly.hms.harvard.edu/archive/2006/0130/stu dent_scene.html

Jamil B, Sethi A, Ali S. Attitude of nursing students towards e-learning. Published online 2016

Janzen BW, Sommerfeld C, Gooi ACC. Effectiveness of eLearning in a Medical School 2.0 Model: Comparison of Item Analysis for Student-Generated vs. Faculty-Generated Multiple-Choice Questions. 2019:184-188

Kapasia N, Paul P, Roy A, et al. Impact of lockdown on learning status of undergraduate and postgraduate students during COVID-19 pandemic in West Bengal, India. Child Youth Serv Rev. Published online 2020:105194. https://doi.org/10.1016/j.childyouth.2020.105194

Larson MJ, Amodeo M, Storti SA, Steketee G, Blitzman G, Smith L. A novel CBT web course for the substance abuse workforce: 
Community counselors' perceptions. Subst Abus. 2009; 30(1):26-39. https://doi.org/10.1080/08897070802611741

Maheshwari S, Zheleva B, Rajasekhar V, Batra B. e-Teaching in pediatric cardiology: A paradigm shift. Ann Pediatr Cardiol. 2015; 8(1):10. https://doi.org/10.4103/09742069.149512

Martín-Blas T, Serrano-Fernández A. The role of new technologies in the learning process: Moodle as a teaching tool in Physics. Comput Educ. 2009; 52(1):35-44. https://doi.org/10.1016/j.compedu.2008.06.005

Muirhead RJ. E-learning: Is This Teaching at Students or Teaching With Students? In: Nursing Forum. Vol 42. Wiley Online Library; 2007:178-184.

https://doi.org/10.1111/j.1744-6198.2007.00085.x

Mukhtar K, Javed K, Arooj M, Sethi A. Advantages, Limitations and Recommendations for online learning during COVID-19 pandemic era. Pakistan J Med Sci. 2020;36(COVID19-S4):S27-S31.

https://doi.org/10.12669/pjms.36.COVID19-S4.2785

Münch-Harrach D, Kothe C, Hampe W. Audio podcasts in practical courses in biochemistry - cost-efficient e-learning in a well-proven format from radio broadcasting. GMS Z Med Ausbild. 2013; 30(4):Doc44.

Offir B, Lev Y, Bezalel R. Surface and Deep Learning Processes in Distance Education: Synchronous versus Asynchronous Systems. Comput Educ. 2008;51:1172-1183. https://doi.org/10.1016/j.compedu.2007.10.009

Ortega-Morán J-F, Pagador B, Maestre-Antequera J, Arco A, Monteiro F, Sánchez-Margallo FM. Validation of the online theoretical module of a minimally invasive surgery blended learning course for nurses: A quantitative research study. Nurse Educ Today. Published online 2020:104406. https://doi.org/10.1016/j.nedt.2020.104406

Owusu-Fordjour C, Koomson CK, Hanson D. The impact of Covid-19 on learning-the perspective of the Ghanaian student. Eur J Educ Stud. Published online 2020.

Pelmin M. Readings on Coronavirus Disease (COVID-19) and the Higher Education Institution (HEls) Emergency Preparedness in the Philippines. Available SSRN 3573896. Published online 2020. https://doi.org/10.2139/ssrn.3573896

Popovici A, Mironov C. Students' perception on using eLearning technologies. Procedia-Social Behav Sci. 2015; 180:1514-1519. https://doi.org/10.1016/j.sbspro.2015.02.300

Projet de décret-loi no 2.20 .292 sur les dispositions relatives à l'état d'urgence sanitaire ainsi que les mesures prises pour lutter contre la propagation de la pandémie du coronavirus. Bulletin officiel du gouvernement marocain. 2020

Qandil AM, Abdel-Halim H. Distance e-learning is closer than everybody thought: A Pharmacy Education Perspective. Heal Prof Educ. Published online 2020.

https://doi.org/10.1016/j.hpe.2020.05.004

Rajhans V, Memon U, Patil V, Goyal A. Impact of COVID-19 on academic activities and way forward in Indian

Optometry. J Optom. Published online 2020.

https://doi.org/10.1016/j.optom.2020.06.002
Roskvist R, Eggleton K, Goodyear-Smith F. Provision of elearning programmes to replace undergraduate medical students' clinical general practice attachments during COVID-19 stand-down. Educ Prim care an Off Publ Assoc Course Organisers, Natl Assoc GP Tutors, World Organ Fam Dr. Published online May 2020:1-8.

https://doi.org/10.1080/14739879.2020.1772123

Simpson A, Reynolds L, Light I, Attenborough J. Talking with the experts: Evaluation of an online discussion forum involving mental health service users in the education of mental health nursing students. Nurse Educ Today. 2008; 28(5):633-640. https://doi.org/10.1016/j.nedt.2007.09.009

Singhal T. A Review of Coronavirus Disease-2019 (COVID19). Indian J Pediatr. 2020;87(4):281-286.

https://doi.org/10.1007/s12098-020-03263-6

Singh D, Alam F, Matava C. A Critical Analysis of Anesthesiology Podcasts: Identifying Determinants of Success. JMIR Med Educ. 2016; 2(2):e14. https://doi.org/10.2196/mededu.5950

Srinivasan DK. Medical Students' Perceptions and an Anatomy Teacher's Personal Experience Using an e-Learning Platform for Tutorials During the Covid-19 Crisis. Anat Sci Educ. 2020; 13(3):318-319. https://doi.org/10.1002/ase.1970

Vitoria L, Mislinawati M, Nurmasyitah N. Students' perceptions on the implementation of e-learning: Helpful or unhelpful. J Phys. 2018;1088. https://doi.org/10.1088/1742$6596 / 1088 / 1 / 012058$

Wang C, Horby PW, Hayden FG, Gao GF. A novel coronavirus outbreak of global health concern. Lancet (London, England). 2020;395(10223):470-

473.https://doi.org/10.1016/S0140-6736(20)30185-9

Watts L. Synchronous and Asynchronous Communication in Distance Learning: A Review of the Literature. Q Rev Distance Educ. 2016;17:23-32

World Health Organisation. WHO Timeline-COVID-19. WHO Timeline-COVID-19

Yilmaz R. Exploring the role of e-learning readiness on student satisfaction and motivation in flipped classroom. Comput Human Behav. 2017; 70:251-260.

https://doi.org/10.1016/j.chb.2016.12.085

Zhang Q, He Y-J, Zhu Y-H, et al. The evaluation of online course of Traditional Chinese Medicine for MBBS international students during the COVID-19 epidemic period. Integr Med Res. Published online 2020:100449. https://doi.org/10.1016/j.imr.2020.100449

Zingaretti N, Contessi Negrini F, Tel A, Tresoldi MM, Bresadola V, Parodi PC. The Impact of COVID-19 on Plastic Surgery Residency Training. Aesthetic Plast Surg. Published online May 2020:1-5. https://doi.org/10.1007/s00266-02001789-w 